\title{
Controle biológico da queima-das-bainhas em arroz pela microbiolização de sementes com bactérias antagonistas
}

\author{
Juliane Ludwig \& Andréa B. Moura \\ Laboratório de Bacteriologia Vegetal, Departamento de Fitossanidade, FAEM, Universidade Federal de Pelotas, \\ CEP 96010-970, Pelotas, RS, Brasil, e-mail: abmoura@ufpel.tche.br
}

Autor para correspondência: Andréa B. Moura

LUDWIG, J. \& MOURA, A.B. Controle biológico da queima-das-bainhas em arroz pela microbiolização de sementes com bactérias antagonistas. Fitopatologia Brasileira 32:381-386. 2007.

\begin{abstract}
RESUMO
Objetivou-se avaliar o efeito de oito isolados bacterianos pré-selecionados de Pseudomonas synxatha, P. fluorescens, Bacillus subtilis, Bacillus sp. e Stenotrophomonas malthophilia no controle da queima-das-bainhas do arroz, causada por Rhizoctonia solani. Sementes da cultivar El Passo L144 foram imersas em suspensão $\left(\mathrm{A}_{540}=0,5\right)$ de cada um dos isolados e agitadas por $30 \mathrm{~min}$ a $10^{\circ} \mathrm{C}$. Sementes imersas somente em solução salina e em salina mais fungicida (Carboxin + Thiran) foram utilizadas como testemunhas. Foram semeadas 10 sementes por vaso, em quatro repetições, dispostas em delineamento completamente casualizado. Foram realizados três ensaios, sendo que no primeiro foi possível selecionar três isolados como promissores, com reduções na severidade da doença atingindo 50, 33,3 e 16,7 \%, respectivamente. Estes isolados foram utilizados nos ensaios posteriores, instalados em casa de vegetação e conduzidos até o ponto de colheita, onde foi possível observar o efeito biocontrolador propiciado, principalmente, pelo isolado de $P$. fluorescens DFs223, com reduções significativas na severidade da doença chegando a 88 e $91,7 \%$ no segundo e terceiro ensaios respectivamente. Em ambos os ensaios, houve incremento tanto do número de panículas quanto do número de perfilhos e da massa seca de raízes em até 42,8, 81,2 e 113\% respectivamente, nas plantas tratadas com o isolado de $P$. fluorescens DFs223.
\end{abstract}

Palavras-chave adicionais: Rhizoctonia solani, Oryza sativa, biocontrole, rizobactérias.

\begin{abstract}
Biological control of rice sheath blight by microbiolization of seeds with antagonist bacteria

Eight pre-selected bacterial strains were evaluated for control of rice sheath blight caused by Rhizoctonia solani, Pseudomonas synxatha, P. fluorescens, Bacillus subtilis, Bacillus sp. and Stenotrophomonas malthopilia. Rice seeds cv. El Passo L144 were treated by immersion in a bacterial suspension $\left(\mathrm{A}_{540}=0.5\right)$ of each isolate under agitation at $10^{\circ} \mathrm{C}$ for 30 min. Seeds immersed in saline solution and in saline plus fungicide (Carboxin + Thiran) were used as control. Ten seeds per pot were used, in four replications, in a completely randomized design. Three assays were performed, and in the first it was possible to select the three strains which reduced the severity of the disease, reaching 50, 33.3 and $16.7 \%$, respectively. These isolates were used in the two last assays, which were maintained in greenhouse until the harvesting stage, where it was possible to observe the biocontrol effect, mainly by the strain of $P$. fluorescens DFs223, with significant reduction in the disease severity, reaching 88 and $91.7 \%$ in the second and third assays, respectively. There was an increase in the number of panicles, as well as in the number of tillers and dry mass of roots, reaching to $42.8,81.2$ and $113 \%$ respectively, in plants treated with this isolate in both assays.
\end{abstract}

Additional keywords: Rhizoctonia solani, Oryza sativa, biocontrol, rhizobacteria.

\section{INTRODUÇÃO}

A cultura do arroz irrigado (Oryza sativa L.) está sujeita ao ataque de várias doenças. Em quase todos os anos ocorrem ataques endêmicos, com perdas na produção e que também interferem na qualidade fisiológica e sanitária das sementes (Ribeiro, 1994).

A queima-das-bainhas do arroz, causada pelo fungo Rhizoctonia solani J.G. Kühn [teleomorfo Thanatephorus

Parte da Dissertação de Mestrado da primeira autora. Universidade Federal de Pelotas. Pelotas RS. 2005. cucumeris (Frank) Donk], é responsável por danos crescentes a cada ano. É uma doença que ocorre tanto em áreas temperadas quanto em tropicais onde se cultiva $o$ arroz dentro de um sistema de produção que utiliza grande quantidade de fertilizantes, principalmente nitrogenados, aliado ao uso de cultivares com alto índice de perfilhamento (Eizenga et al., 2002).

Condições de luminosidade baixa, umidade alta e temperaturas médias em torno de $28-32{ }^{\circ} \mathrm{C}$ são favoráveis à ocorrência da doença (Lee \& Rush, 1993). Os sintomas se iniciam por lesões na bainha, na altura da lâmina de água, mas, em condições favoráveis à evolução da doença, podem ser observados nas bainhas e folhas superiores (Ou, 1985). Escleródios do fungo sobrevivem no solo e são disseminados 
pela água de irrigação, infectando folhas e bainhas até a base da haste (Rabindran \& Vidhyasekaran, 1996).

Por ser um patógeno com grande capacidade de sobrevivência (Prabhu et al., 1999) e ampla gama de hospedeiros (Prabhu et al., 2002; Nunes et al., 2004), há grande dificuldade no controle do mesmo. Embora o uso de cultivares resistentes seja desejável, as cultivares de arroz utilizados no Brasil, que exibem um nível aceitável de resistência para queima-das-bainhas, não são viáveis para a comercialização (Rodrigues et al., 2003).

Dentre as possibilidades de controle, o químico não se apresenta viável, haja certo que é de difícil execução e alto custo, podendo resultar em contaminações do solo, bem como no surgimento de populações resistentes do patógeno (Nagarajkumar et al., 2004). Assim torna-se essencial a busca por outras formas de controle, sendo o controle biológico uma alternativa viável.

O uso de biocontroladores, principalmente espécies de Bacillus e Pseudomonas, é citado para o controle da queima-das-bainhas (Nandakumar et al., 2001; Commare et al., 2002; Wiwattanapatapee et al., 2004), além de outras doenças do arroz como a bruzone causada por Pyricularia oryzae Sacc. (Vidhyasekaran et al., 1997), "bakanae disease" causada por Fusarium fujikuroi Nirenberg (citado como Fusarium moniliforme J. Sheld.) (Rosales \& Mew, 1997) e galhas causadas por Meloidogyne graminicola Golden e Birchfield (Padgham \& Sikora, 2006), aplicados, principalmente, por microbiolização das sementes.

Este trabalho teve por objetivo avaliar o potencial de biocontrole da queima-das-bainhas do arroz por bactérias dos gêneros Pseudomonas, Bacillus e Stenotrophomonas, pré-selecionadas para o controle de Bipolaris oryzae (Breda de Haan) Shoemaker, microbiolizadas às sementes.

\section{MATERIAL E MÉTODOS}

\section{Isolados bacterianos e fúngicos}

Os isolados bacterianos utilizados (Tabela 1) foram pré-selecionados em bioensaio para o controle de $B$. oryzae por Moura et al. (1998) recebendo a denominação DFs (Departamento de Fitossanidade). Os isolados fazem parte da coleção do Laboratório de Bacteriologia Vegetal da Universidade Federal de Pelotas e foram identificados por sequenciamento do gene $16 \mathrm{~S}$ rDNA (dados ainda não publicados). O fungo $R$. solani foi isolado de plantas de arroz apresentando sintomas de queima-das-bainhas, coletadas na cidade de Pelotas, Rio Grande do Sul.

\section{Microbiolização das sementes}

Bactérias foram repicadas para meio sólido 523 de Kado \& Heskett (1970) e incubadas a $28{ }^{\circ} \mathrm{C}$ por $24 \mathrm{~h} \mathrm{em}$ B.O.D. Prepararam-se suspensões, a partir dessas culturas, em solução salina $(\mathrm{NaCl} 0,85 \%)$, sendo a concentração ajustada para $\mathrm{A}_{540}=0,5$. As sementes da cultivar El Passo L144 foram microbiolizadas nestas suspensões, sob agitação, durante 30 minutos, à temperatura de $10^{\circ} \mathrm{C}$. Como testemunha, sementes foram imersas em solução salina $(\mathrm{T})$ ou em solução salina mais o fungicida Carboxin + Thiran $(\mathrm{T}+\mathrm{F})$, na concentração final de $3 \mathrm{~mL} / \mathrm{kg}$ de sementes, segundo indicação de Arroz Irrigado (1999) para o controle das principais doenças fúngicas do arroz veiculadas pelas sementes.

\section{Instalação dos ensaios}

Foram instalados três ensaios em casa-de-vegetação não climatizada. $O$ primeiro foi conduzido em vasos contendo $1 \mathrm{~kg}$ de solo (Planossolo), não esterilizado, misturado à areia, na proporção de $3: 1$, sendo a correção dos macronutrientes realizada segundo Comissão... (1999). Foram depositadas 10 sementes por vaso. Por ocasião da emissão da segunda folha (estádio V2) realizou-se o desbaste, deixando-se quatro plantas por vaso. $\mathrm{O}$ delineamento foi inteiramente casualizado, com quatro repetições. Esse ensaio foi conduzido no período de abril a maio de 2004, cuja média diária de temperatura foi de $16,4^{\circ} \mathrm{C}$.

$\mathrm{O}$ segundo e terceiro ensaios foram realizados de maneira similar, porém em vasos com capacidade para $7 \mathrm{~kg}$, nos períodos de setembro de 2004 a janeiro de 2005 e janeiro de 2006 a maio de 2006, sendo as médias diárias de temperatura nos períodos de $25{ }^{\circ} \mathrm{C}$ e $24,3{ }^{\circ} \mathrm{C}$, respectivamente.

Nestes dois ensaios, após o aparecimento da segunda

TABELA 1 - Identificação e habitat dos isolados bacterianos utilizados para microbiolizar sementes de arroz

\begin{tabular}{lll}
\hline \hline Isolados & \multicolumn{1}{c}{ Identificação } & \multicolumn{1}{c}{ Habitat } \\
\hline DFs185 & Pseudomonas synxatha (Ehrenberg)Holland & Sementes de arroz \\
DFs223 & P. fluorescens Migula & Sementes de arroz \\
DFs306 & Não identificado & Sementes de cebola \\
DFs416 & Bacillus sp. & Contaminantes indicadores de antibiose \\
DFs418 & Bacillus sp. & Contaminantes indicadores de antibiose \\
DFs419 & Bacillus sp. & Contaminantes indicadores de antibiose \\
DFs422 & B. subtilis (Ehrenberg) Cohn & Contaminantes indicadores de antibiose \\
DFs471 & Stenotrophomonas maltophilia (Hugh) Palleroni \& Bradbury & Túnica de alho \\
\hline
\end{tabular}


folha (estádio V2), as plantas foram desbastadas, deixandose duas por vaso. Foram usados os três isolados DFs185, DFs223 e DFs306, que proporcionaram resultados mais promissores no primeiro ensaio, bem como as testemunhas $\mathrm{T}$ e T+F. Em todos os ensaios, o solo foi mantido encharcado através de duas irrigações diárias conforme recomendado por Dode (1993).

\section{Preparo do inóculo de $R$. solani}

O inóculo foi preparado seguindo a metodologia descrita por Dode (1993) com modificações, onde grãos de arroz com casca (75\%) e casca de arroz (25\%), foram misturados em Erlenmeyer de $250 \mathrm{~mL}$. Esse substrato foi umedecido com água destilada, acrescentando-se $5 \mathrm{~g}$ de sacarose por Erlenmeyer. O substrato, após autoclavado, foi transferido para placas de Petri esterilizadas, para as quais foram repicadas quatro porções de meio de cultura colonizado por $R$. solani. As placas foram mantidas por sete dias à temperatura de $22 \pm 2{ }^{\circ} \mathrm{C}$ para a completa colonização do substrato.

\section{Infestação do solo}

Após o início da emissão da quarta folha (estádio V3), o solo foi infestado com $R$. solani. O meio colonizado foi triturado manualmente com auxilio de um bastão de vidro, sendo posteriormente distribuído uniformemente na quantidade de $4 \mathrm{~g}$ por vaso. As infestações foram realizadas com intervalos de 10 dias, perfazendo três vezes para o primeiro ensaio, e de 30 dias, até a floração, totalizando quatro vezes para o segundo e terceiro ensaios. As plantas foram mantidas em câmara úmida $24 \mathrm{~h}$ antes e $48 \mathrm{~h}$ depois da infestação.

\section{Avaliação}

No primeiro ensaio, as plantas foram avaliadas sete dias após a última infestação do solo, segundo a severidade da doença, atribuindo-se notas de 1 a 9 , de acordo com a intensidade de sintomas e porcentagem de área infectada (International..., 1975). As plantas coletadas tiveram a parte aérea separada do sistema radicular, por corte realizado na altura do colo. As raízes foram lavadas com água corrente sobre uma peneira. Ambas as partes foram colocadas, separadamente, em sacos de papel em estufa à $60{ }^{\circ} \mathrm{C}$ por quatro dias. Após esse período foram mensuradas as massas secas da parte aérea (MSA) e das raízes (MSR).

As avaliações, do segundo e terceiro ensaios, foram realizadas quando a maioria das plantas encontrava-se no ponto de colheita. Foram avaliadas a severidade da doença (Nota) e a massa seca de raízes (MSR), bem como o número de panículas (NPA) e o número de perfilhos (NPE). Os dados foram submetidos à análise de variância e as médias foram comparadas pelo teste de Tukey a $5 \%$ de probabilidade sendo esta realizada utilizando-se o programa $\mathrm{SAS}^{\circledR}$ (versão Learning Edition 1.0) (Statistical Analysis System, 2002). Os dados de severidade (Nota) foram transformados para $\sqrt{\mathrm{X}+5}$.

\section{RESULTADOS}

No primeiro ensaio (Tabela 2), observou-se tendência dos isolados DFs185, DFs223 e DFs306 quanto à redução da severidade, chegando a 50,33,3 e $16,7 \%$ respectivamente, resultando também em aumento da massa seca da parte aérea e/ou radicular, embora não tenham ocorrido diferenças estatísticas.

No segundo ensaio, o isolado DFs223 destacou-se dos demais tratamentos em todas as variáveis avaliadas (Tabela 3). No que se refere à severidade (Nota), este proporcionou um nível de controle de $88,8 \%$ sendo estatisticamente superior à testemunha, seguido pelo isolado DFs185, cujo controle foi de $50 \%$. Não houve diferença significativa entre os demais tratamentos. Ao avaliar-se o número de panículas (NPA) e o número de perfilhos (NPE) o isolado DFs223 continuou se mostrando o melhor dentre todos os tratamentos, sendo estatisticamente superior à testemunha em 42,8 e $81,2 \%$, respectivamente. Relacionado ao peso da matéria seca de raízes (MSR), o isolado DFs223 mostrou-se significativamente superior a todos os tratamentos, incrementando em 113\% em relação à testemunha (Tabela 3).

No terceiro ensaio, o isolado DFs223 foi o que novamente demonstrou o melhor desempenho, propiciando reduções significativas na severidade da doença chegando a 91,7 e $87,5 \%$ em relação à testemunha e à testemunha com o fungicida, respectivamente (Tabela 3 ).

No que se refere ao número de panículas (NPA) e

TABELA 2 - Notas segundo a intensidade de área infectada, massa seca da parte aérea (MSA) (g) e massa seca de raízes (MSR) (g) de plantas oriundas de sementes microbiolizadas com diferentes isolados bacterianos e conduzidas em solo infestado por $R$. solani, em casa de vegetação (primeiro ensaio)

\begin{tabular}{lcrr}
\hline \hline Tratamento & Nota & MSA & MSR \\
\hline DFs185 & $1,5 \mathrm{a}^{1}$ & $0,23 \mathrm{a}^{1}$ & $0,48 \mathrm{a}^{1}$ \\
DFs223 & $2,0 \mathrm{a}$ & $0,21 \mathrm{a}$ & $0,42 \mathrm{a}$ \\
DFs306 & $2,5 \mathrm{a}$ & $0,19 \mathrm{a}$ & $0,55 \mathrm{a}$ \\
DFs416 & $4,0 \mathrm{a}$ & $0,19 \mathrm{a}$ & $0,51 \mathrm{a}$ \\
DFs418 & $6,0 \mathrm{a}$ & $0,21 \mathrm{a}$ & $0,63 \mathrm{a}$ \\
DFs419 & $6,0 \mathrm{a}$ & $0,23 \mathrm{a}$ & $0,39 \mathrm{a}$ \\
DFs422 & $5,0 \mathrm{a}$ & $0,16 \mathrm{a}$ & $0,40 \mathrm{a}$ \\
DFs471 & $5,0 \mathrm{a}$ & $0,21 \mathrm{a}$ & $0,44 \mathrm{a}$ \\
T & $3,0 \mathrm{a}$ & $0,19 \mathrm{a}$ & $0,45 \mathrm{a}$ \\
T+F & $5,0 \mathrm{a}$ & $0,18 \mathrm{a}$ & $0,48 \mathrm{a}$ \\
\hline C.V. & $30,39^{*}$ & 12,61 & 24,7 \\
\hline
\end{tabular}

${ }^{1}$ Médias seguidas de mesma letra, na coluna, não diferem entre si pelo teste de Tukey à $5 \%$, em quatro repetições; $\mathrm{T}=$ testemunha tratada com salina, $\mathrm{T}+\mathrm{F}=$ testemunha tratada com salina mais o fungicida Carboxin + Thiran

*Coeficiente de variação dos valores transformados para $\sqrt{\mathrm{X}+5}$ 
TABELA 3 - Notas segundo a intensidade de área infectada, número de panículas (NPA), número de perfilhos (NPE) e massa seca de raízes (MSR) (g) de plantas oriundas de sementes microbiolizadas com diferentes isolados bacterianos e conduzidas em solo infestado por $R$. solani, em casa de vegetação (segundo ensaio e terceiro ensaios)

\begin{tabular}{|c|c|c|c|c|c|c|c|c|}
\hline \multirow[b]{2}{*}{ Tratamento } & \multicolumn{2}{|c|}{ Nota } & \multicolumn{2}{|c|}{ NPA } & \multicolumn{2}{|c|}{ NPE } & \multicolumn{2}{|c|}{ MSR } \\
\hline & $\begin{array}{c}2^{\circ} \\
\text { ensaio }\end{array}$ & $\begin{array}{c}3^{\mathbf{o}} \\
\text { ensaio }\end{array}$ & $\begin{array}{c}2^{\circ} \\
\text { ensaio }\end{array}$ & $\begin{array}{c}3^{\circ} \\
\text { ensaio }\end{array}$ & $\begin{array}{c}2^{\circ} \\
\text { ensaio }\end{array}$ & $\begin{array}{c}3^{\mathbf{0}} \\
\text { ensaio }\end{array}$ & $\begin{array}{c}2^{\circ} \\
\text { ensaio } \\
\end{array}$ & $\begin{array}{c}3^{\circ} \\
\text { Ensaio } \\
\end{array}$ \\
\hline DFs 185 & $3,0 \mathrm{ab}^{1}$ & $3,0 \mathrm{a}^{1}$ & $3,5 b^{1}$ & $15,9 a^{1}$ & $4,0 b^{1}$ & $15,9 a^{1}$ & $11,65 b c^{1}$ & $18,97 \mathrm{bc}^{1}$ \\
\hline DFs223 & $0,67 \mathrm{~b}$ & $0,5 \mathrm{~b}$ & $5,0 \mathrm{a}$ & $17,9 \mathrm{a}$ & $7,25 \mathrm{a}$ & $17,9 \mathrm{a}$ & $31,88 \mathrm{a}$ & $27,53 \mathrm{a}$ \\
\hline DFs306 & $4,3 \mathrm{ab}$ & $3,5 \mathrm{a}$ & $4,0 \mathrm{ab}$ & $17,6 \mathrm{a}$ & $5,5 \mathrm{ab}$ & $17,6 \mathrm{a}$ & $17,72 b$ & $23,84 \mathrm{ab}$ \\
\hline $\mathrm{T}$ & $6,0 \mathrm{a}$ & $6,0 \mathrm{a}$ & $3,5 b$ & $13,1 b$ & $4,0 \mathrm{~b}$ & $13,1 \mathrm{~b}$ & $14,97 \mathrm{~b}$ & $16,92 \mathrm{~cd}$ \\
\hline $\mathrm{T}+\mathrm{F}$ & $4,0 \mathrm{ab}$ & $4,0 \mathrm{a}$ & $3,75 \mathrm{ab}$ & $13,6 b$ & $5,5 \mathrm{ab}$ & $13,6 b$ & $5,4 \mathrm{c}$ & $11,37 d$ \\
\hline C.V. & $21,49^{*}$ & $15,5^{*}$ & 10,24 & 3,29 & 15,73 & 3,29 & 13,54 & 12,55 \\
\hline $\begin{array}{l}{ }^{1} \text { Médias seg } \\
\text { em quatro }\end{array}$ & $\begin{array}{l}\text { de } n \\
\text { ições }\end{array}$ & letr & - & não & rem & si & este d & 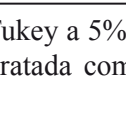 \\
\hline
\end{tabular}

número de perfilhos (NPE), todos os isolados diferiram estatisticamente da testemunha e da testemunha com o fungicida, notando-se a tendência de superioridade dos isolados DFs223 e DFs306. A massa seca de raízes (MSR) também foi incrementada significativamente pela maioria dos isolados, merecendo destaque o isolado DFs223 que aumentou a massa em 63 e 78 \%, em relação à testemunha e à testemunha com o fungicida, respectivamente.

\section{DISCUSSÃO}

Os isolados DFs185, DFs223 e DFs306 foram selecionados como agentes promissores de controle biológico devido à redução na severidade da doença, bem como ao incremento do peso da matéria seca de raízes e parte aérea alcançando, em níveis iguais ou até mesmo superiores aos propiciados pelo tratamento com fungicida.

A ausência de controle por parte do fungicida, pode ser explicada pelo fato de o mesmo não ser recomendado para o controle da queima-das-bainhas, não conferindo proteção da planta ao ataque de $R$. solani, porém utilizado rotineiramente pelos produtores de arroz.

Outro efeito deletério do uso do fungicida foi observado no segundo e terceiro ensaios, quando resultou em redução da massa radicular, possivelmente devido ao amplo espectro de ação do mesmo, afetando negativamente a microbiota da rizosfera (Araújo \& Araújo, 2006). O efeito negativo de fungicidas sobre variáveis que avaliam o crescimento vegetativo bem como aquelas relacionadas à interação entre microorganismos e plantas foi relatado por Oliveira et al. (1999), quando observaram redução da massa seca de nódulos e de raízes, além do número de nódulos em plantas de alfafa cujas sementes foram microbiolizadas com as estirpes SEMIA 134 ou SEMIA 135 de Rhizobium meliloti Dangeard e tratadas com o fungicida Thiram.
$\mathrm{O}$ isolado biocontrolador mais eficiente no primeiro ensaio (DFs185) e nos segundo e terceiro ensaios (DFs223) foram diferentes. Como as avaliações de severidade foram realizadas em estádios de desenvolvimento distintos (primeiro ensaio durante o início do perfilhamento e, o segundo e terceiro, no ponto de colheita), acredita-se que este fator possa ter contribuído com a diferença em relação ao comportamento dos isolados em cada um dos ensaios. Variações em relação à suscetibilidade de plantas de arroz a $R$. solani nos diferentes estádios de desenvolvimento da planta de arroz são relatados e, embora haja certa discordância entre autores, os estádios de plântula (Lee \& Rush, 1983), emborrachamento (Sharma \& Teng, 1990) e florescimento (Sharma \& Teng, 1990; Dode, 1993) são apontados como os de maior sensibilidade.

Há, ainda, a possibilidade de ocorrência de redução do efeito do biocontrolador após um período de tempo. A diminuição do efeito biocontrolador ao longo do tempo foi relatada para diferentes isolados de Bacillus megaterium de Bary, que passados 20 dias de sua aplicação, não possibilitaram mais a redução do progresso da queimadas-bainhas em arroz (Wiwattanapatapee et al., 2004) e da podridão das raízes em soja (Zheng \& Sinclair, 2000) ambos causados por $R$. solani. Este fato também poderia colaborar para explicar o comportamento distinto dos isolados biocontroladores nos diferentes ensaios do presente trabalho caso fossem realizadas avaliações da severidade da doença ao longo do tempo, o que não ocorreu.

No entanto, no presente trabalho, pôde-se observar a manutenção deste efeito em diferentes estádios de desenvolvimento e avaliação, principalmente nas plantas tratadas com o isolado DFs223, uma vez que as plantas originadas de sementes microbiolizadas com este isolado mostraram sintomas menos severos da doença e ainda conseguiram incrementar a massa seca de raízes ao final do ciclo (Tabela 3). 
Para o controle ser alcançado, mesmo ao final do ciclo da cultura, geralmente é necessário que a população de bactérias biocontroladoras se mantenha alta (Huang et al., 2004). Esta premissa parece ter sido cumprida pela microbiolização das sementes, pois estando os biocontroladores presentes desde o início do processo germinativo e sendo estes capazes de colonizar o sistema radicular das plantas de arroz (Zanatta et al., 2004), provavelmente se estabeleceram na rizosfera. É possível que estas bactérias possam também ter colonizado, a partir das sementes, tecidos da parte aérea como ocorrido nos trabalhos desenvolvidos por Mew \& Rosales (1986) e Vidhyasekaran et al., (1997).

Os isolados selecionados (DFs185, DFs223 e DFs306) podem ser considerados como promissores, mesmo quando seus efeitos são comparados aos proporcionados por isolados utilizados para o controle da queima-das-bainhas em arroz por outros pesquisadores. Os referidos trabalhos foram realizados em solo naturalmente infestados por $R$. solani (Thara \& Gnanamanickam, 1994) ou foram infestados com um (Rabindran \& Vidhyasekaran, 1996) ou dois escleródios por planta (Commare et al., 2002), em uma única aplicação, entre 35 e 60 dias após o transplantio, o que é inferior ao número de inoculações, e, provavelmente, à quantidade de inóculo utilizados no presente trabalho.

O potencial dos isolados aqui selecionados, é elevado e pode ser ampliado, caso se associem estratégias como o uso combinado de isolados ou destes com compostos que estimulem sua atividade. Os benefícios destas estratégias foram mostrados por Commare et al. (2002), que trabalhando com uma formulação à base de dois isolados de P. fluorescens suplementado com quitina relataram redução de $63 \%$ na severidade da queima-das-bainhas em arroz. Resultados similares foram obtidos por Domenech et al. (2006), que adicionaram um isolado de $P$. fluorescens a um produto biológico já formulado (LS213) e observaram redução de $75 \%$ na severidade do tombamento de mudas de tomate por até três semanas após o tratamento.

Outra forma de potencializar os efeitos biocontroladores se refere ao modo como estes são dispensados, uma vez que, tanto a população da rizosfera quanto da filosfera participam da redução da doença (Rabindran \& Vidhyasekaran, 1996). Em geral, é necessária a combinação de métodos de aplicação dos biocontroladores para alcançar resultados satisfatórios em termos de redução de severidade da queima-das-bainhas e aumento na produção (Thara \& Gnanamanickam, 1994; Rabindran \& Vidhyasekaran, 1996; Nandakumar et al., 2001; Commare et al., 2002).

Assim, pode-se considerar viável o uso dos biocontroladores selecionados para o controle da queimadas-bainhas do arroz, tanto pela capacidade destes em reduzir a doença, quanto pela possibilidade de aumentar sua eficiência, utilizando-os associados às estratégias acima mencionadas. Este potencial é reforçado por se tratar de tecnologia de baixo custo econômico e ambiental.

\section{AGRADECIMENTOS}

Os autores agradecem à Coordenação de Aperfeiçoamento de Pessoal de Nível Superior - CAPES pela bolsa de mestrado concedida ao primeiro autor.

\section{REFÊRENCIAS BIBLIOGRÁFICAS}

ARAÚJO, A.S.F. \& ARAÚJO, R.S. Sobrevivência e nodulação de Rhizobium tropici em sementes de feijão tratadas com fungicidas. Ciência Rural 36:973-976. 2006.

ARROZ IRRIGADO: Recomendações técnicas da pesquisa para o sul do Brasil. Pelotas RS. 1999.

COMMARE, R.J., NANDAKUMAR, R., KANDAM,A., SURESH, S., BHARATHI, M., RAGUCHANDER, T. \& SAMIYAPPAN, R. Pseudomonas fluorescens based bio-formulation for the management of sheath blight disease and leaffolder insect in rice. Crop Protection 21:671-677. 2002.

COMISSÃO DE FERTILIDADE DE SOLO - RS/SC. Recomendações de adubação e de calagem para os estados do Rio Grande do Sul e de Santa Catarina. 3a.ed. Pelotas, 1999.

DODE, L.B. Avaliação da resistência de arroz à queima-dasbainhas (Rhizoctonia solani Künh) através de diferentes métodos. Dissertação de Mestrado. Pelotas RS. Universidade Federal de Pelotas. 1993.

DOMENECH, J., REDDY, M.S., KLOEPPER, J.W., RAMOS, B. \& GUTIERREZ-MAÑERO, J. Combined application of the biological product LS213 with Bacillus, Pseudomonas or Chryseobacterium for growth promotion and biological control of soil-borne disease in pepper and tomato. BioControl 51:245-258. 2006.

EIZENGA, G.C., LEE, F.N. \& RUTGER, J.N. Screening Oryza species plants for rice sheath blight resistance. Plant Disease 86:808-812. 2002.

HUANG, Z., BONSAL, R.F., MAVRODI, D.V., WELLER, D.M. \& THOMASHOW, L.S. Transformation of Pseudomonas fluorescens with genes for biosynthesis os phenazine-1-carboxylic acid improves biocontrol of rhizoctonia root rot in situ antibiotic production. FEMS Microbiology Ecology 49:243-251. 2004.

INTERNATIONAL RICE RESEARCH INSTITUTE. Sistema de Evaluación Stándart para Arroz. Los Baños. 1975.

KADO, C.I. \& HESKETT, M.S. Seletive media for isolation of Agrobacterium, Corynebacterium, Erwinia, Pseudomonas and Xanthomonas. Phytophathology 60:969-976. 1970.

LEE, F.N. \& RUSH, M.C. Rice sheath bligth: a major rice disease. Plant Disease 67:829-832. 1983.

MEW, T.W. \& ROSALES, A.M. Bacterization of rice plants for control of sheath blight caused by Rhizoctonia solani. Phytopathology 76:1263-1264. 1986.

MOURA, A.B., PIEROBOM, C.R., NAVA, D.E. \& AFONSO, A.P. Tratamento de sementes de arroz para seleção massal de procariotas potenciais antagonistas a Bipolaris oryzae. Fitopatologia Brasileira 
23(Supl.):213. 1998.

NAGARAJKUMAR, M., BHASKARAN, R. \& VELAZHAHAN, R. Involvement of secondary metabolites and extracellular lytic enzymes produced by Pseudomonas fluorescens in inhibition of Rhizoctonia solani, the rice sheath bligth pathogen. Microbiological Research 159:73-81. 2004.

NANDAKUMAR, R., BABU, S., VISWANATHAN, R., RAGUCHANDER, T. \& SAMIYAPPAN, R. Induction of systemic resitance in rice against sheath blight disease by Pseudomonas fluorescens. Soil Biology and Biochemistry 33:603-612. 2001.

NUNES, C.D., RIBEIRO, A.S. \& TERRES, A.L. Principais doenças do arroz irrigado e seu controle. In: Gomes, A.S. \& Magalhães Junior, A.M. (Eds.) Arroz irrigado no sul do Brasil. Brasília DF. Embrapa Informação Tecnológica. 2004. pp. 579-633.

OLIVEIRA, P.P.A, TSAI, S.M., CORSI, M. \& DÍAZ, M.D.P. Interação entre cultivares, estirpes comerciais e Rhizobium meliloti e fungicidas no incremento da produção de alfafa. Pesquisa Agropecuária Brasileira 34:425-431. 1999.

OU, S.H. Rice disease. $2^{\text {th }}$ Ed. Kew. Commonwealth Mycological Institute. 1985.

PADGHAM, J. \& SIKORA, R. The potential for Meloidogyne graminicola biological control in rice under oxic and anoxic soil environments. Bulletin-OILB/SRPO 29:111-116. 2006.

PRABHU, A.S., FILIPPI, M.C. \& RIBEIRO, A.S. Doenças e seu controle. In: Vieira, N.R.A.A., Santos, A.B. \& Sant'Ana, E.P. (Eds.) A cultura do arroz no Brasil. Santo Antônio de Goiás GO. Embrapa Arroz e Feijão. 1999. pp. 262-307.

PRABHU, A.S., FILIPPI, M.C., SILVA, G.B. \& SANTOS, G.R. Resistência de cultivares de arroz a Rhizoctonia solani e Rhizoctonia oryzae. Pesquisa Agropecuária Brasileira 37:589-595. 2002.

RABINDRAN, R. \& VIDHYASEKARAN, P. Development of a formulation of Pseudomonas fluorescens PfALR2 for management of rice sheath bligth. Crop Protection 15:715-721. 1996.

RIBEIRO, A.S. Avaliação crítica dos projetos do PNP- Arroz na área de fitopatologia, no período de 1980 a 1990 - Estados do Rio
Grande do Sul e Santa Catarina. Anais, 4 ${ }^{\text {a }}$ Reunião Nacional de Pesquisa do Arroz Irrigado, Goiânia GO. 1994. pp. 177-213.

RODRIGUES, F.A., VALE, F.X.R., DATNOFF, L.E., PRABHU, A.S. $\&$ KORNDÖRFER, G.H. Effect of rice growth stages and silicon on sheath bligth development. Phytopathology 93:256-261. 2003.

ROSALES, A.M. \& MEW, T.W. Supression of Fusarium moniliforme in rice by rice-associated antagonistic bacteria. Plant Disease 81:49-52. 1997.

SHARMA, N.R. \& TENG, P.S. Effect of rice growth stage on sheath bligth development and yeld loss. IRRN 15:19-20. 1990.

STATISTICAL ANALYSIS SYSTEM. SAS: Statistical Analysis System-Getting Started with the SAS Learning Edition. Cary, NC: SAS Institute Inc. 2002.

THARA, K.V. \& GNANAMANICKAM, S.S. Biological control of rice sheath blight in India: lack of correlation between chitinase production by bacterial antagonist and sheath blight supression. Plant and Soil 160:277-280. 1994.

VIDHYASEKARAN, P., RABINDRAN, R., MUTHAMILAN, M., NAYAR, K., RAJAPPAN, K., SUBRAMANIAN, N. \& VASUMATHI, K. Development of o powder formulation of Pseudomonas fluorescens for control of rice blast. Plant Pathology 46:291-297. 1997.

WIWATTANAPATAPEE, R., PENGOO, A., KANJANAMANEESATHIAN M., MATCHAVANICH, W., NILRATANA, L. \& JANTHARANGSRI, A. Floating pellets containing bacterial antagonist for control sheath blight of rice: formulations, viability and bacterial release studies. Journal of Controlled Release 95:455-462. 2004.

ZANATTA, Z.C.N., SCHAFER, J.T., MOURA, A.B., LUDWIG, J. \& SANTOS, A.S. Colonização do sistema radicular de sementes de arroz por rizobactérias biocontroladoras e promotoras de crescimento. Fitopatologia Brasileira 29(Supl.):175. 2004.

ZHENG, X.Y. \& SINCLAIR, J.B. The effects of traits of Bacillus megaterium on sedd and root colonization and their correlation with the suppression of Rhizoctonia root rot of soybean. BioControl 45:223-243. 2000. 